\title{
Deficiency areas in decision making in undergraduate medical students
}

This article was published in the following Dove Press journal:

Advances in Medical Education and Practice

16 July 2014

Number of times this article has been viewed

\author{
Zalika Klemenc-Ketis ${ }^{1,2}$ \\ Janko Kersnik ${ }^{1,2}$ \\ 'Department of Family Medicine, \\ Maribor Medical School, Maribor \\ ${ }^{2}$ Department of Family Medicine, \\ Ljubljana Medical School, Ljubljana, \\ Slovenia
}

Correspondence: Zalika Klemenc-Ketis Maribor Medical School, I Kersnikova Road, Velenje 3320, Slovenia

$\mathrm{Tel} / \mathrm{Fax}+38659030250$

Email zalika.klemenc@um.si
Background: In family medicine, decisions can be difficult due to the early presentation of often poorly developed symptoms or the presentation of undifferentiated conditions that require competencies unique to family medicine, such as; primary care management, specific problemsolving skills, and a comprehensive and holistic approach to be taught to medical students.

Purpose: The aim of this study was to assess the decision-making process covering all theoretical aspects of family practice consultation and to recognize possible areas of deficiency in undergraduate medical students.

Materials and methods: This was a cross-sectional, observational study performed at the Medical School of the University of Maribor in Slovenia. The study population consisted of 159 fourth-year medical students attending a family medicine class. The main outcome measure was the scores of the students' written reports on solving the virtual clinical case. An assessment tool consisted of ten items that could be graded on a 5-point Likert scale.

Results: The final sample consisted of 147 (92.5\%) student reports. There were 95 (64.6\%) female students in the sample. The mean total score on the assessment scale was $35.1 \pm 7.0$ points of a maximum 50 points. Students scored higher in the initial assessment items and lower in the patient education/involvement items. Female students scored significantly higher in terms of total assessment score and in terms of initial assessment and patient education/involvement.

Conclusion: Undergraduate medical education should devote more time to teaching a comprehensive approach to consultation, especially modification of the health behavior of patients and opportunistic health promotion to patients. Possible sex differences in students' performance should be further evaluated.

Keywords: assessment, family medicine, undergraduate medical education, decision making

\section{Introduction}

Decision making is an important part of every consultation. In family medicine, decisions can be difficult, due to the early presentation of often poorly developed symptoms or the presentations of undifferentiated conditions, ${ }^{1,2}$ which require competencies unique to family medicine, such as; primary care management, specific problem-solving skills, and a comprehensive and holistic approach to be taught to medical students. ${ }^{3}$

During a family medicine course, students should recognize and learn that consultation in family medicine consists of four parts: management of presenting problems, modification of help-seeking behaviors, management of continuing problems, and opportunistic health promotion. ${ }^{4}$ Therefore, teaching these tasks is often one of the priorities in a family medicine course curriculum, because the majority of the undergraduate curriculum is devoted to clinical specialties, ${ }^{5}$ with crucial emphasis on teaching 
students about only one aspect of patient management: the clinical management of presenting problems. Family medicine teaching should therefore' complementarily focus also on the other three parts of patient management. ${ }^{3}$

The majority of published studies have focused on clinical management of presenting problems, especially on setting the diagnosis and selection of a proper treatment. ${ }^{6-9}$ Study results showed that undergraduate students have problems in relation to; making a diagnosis, prioritizing, asking for help, and multitasking. ${ }^{6}$ However, there are few studies that have focused on factors that might have influenced academic performance and decision making in medical students. Most of them have dealt with sex differences in learning and academic performance. Extensive research in the field of learning in general, has shown that there are significant differences in the learning styles of men and women. ${ }^{10}$ When it comes to medical education, it seems that female students have a broader range of sensory modality combinations within their preference profiles than male students. ${ }^{11}$ Some studies also showed that female students performed higher in exams and other academic activities compared to their male colleagues, ${ }^{12,13}$ but others showed that male students were more successful ${ }^{14}$ or that there were no sex differences. ${ }^{15}$

To our knowledge, no previous studies have dealt with the assessment of decision making in undergraduate students in terms of modification of help-seeking behaviors, management of continuing problems, and opportunistic health promotion. Therefore, the aim of this study was to assess decision making in undergraduate medical students in terms of covering all aspects of consultation and to recognize possible areas of deficiency. We also wanted to determine whether students' sex was correlated with assessment scores.

\section{Materials and methods}

We performed a cross-sectional observational study in the Medical School of the University of Maribor in Slovenia. The ethics committee of the Department of Family Medicine approved the study protocol. The study took place during the class of family medicine. We included all fourth-year medical students $(n=159)$ enrolled in the study years 2009/2010 and 2010/2011.

At Maribor University, family medicine is part of the mandatory 6-year undergraduate curriculum in the fourth and sixth study year (seventh and eleventh semesters). The following teaching methods are applied in the seventh semester; lectures, written and oral seminars, practice skills exercises, practical exercises in family medicine practice, and individual student assignments. As part of individual assignments, students have to solve a problem-based learning case based on the virtual clinical case scenario. ${ }^{16}$

To be included in the study students had to be; enrolled in the fourth-year of undergraduate medical study, regularly attend classes in family medicine in the study years 2009/2010 and 2010/2011, regularly attend problem-based learning with virtual case exercises, and attend the final assessment of problem-based learning with virtual cases.

At the end of the seventh semester, students attend the seminar work on problem-based learning with virtual clinical case scenarios, which lasts for 3 hours. Students are taught how to solve clinical cases in family medicine with; lectures, small-group work, one-to-one teaching, and discussion. To assess their knowledge, each student receives an individual virtual clinical case scenario. An example of a clinical case scenario is as follows:

Hello!

I am a 55-year-old woman. I have high cholesterol, for which I take pills. I am also in menopause, and experience hot flushes and shortness of breath. I do not take any hormones. My blood pressure is normal, and so is my pulse. I have pain in the lumbar spine, due to a sedentary lifestyle. Sometimes, I feel tingling in my left arm and leg. Yesterday, I felt tightness in the chest for 2 hours; I also felt shortness of breath. This has already happened a couple of times before, but it had never lasted for so long. Today, I feel better. I had the same problems 6 years ago, and the doctor performed several tests (laboratory tests, ultrasound, cycloergometry) and said that this happened due to mental stress. Please, can you give me your advice? Thank you!

$\mathrm{He} / \mathrm{she}$ has to write a short report on how he/she would solve it in a family medicine practice. The report should consist of the following parts; decisions, counseling, referrals, and interventions. Then one teacher assesses their reports.

In Slovenia, there are several freely available e-forums dealing with medical and health issues. For the purpose of the aforementioned exercise, we use virtual clinical case scenarios from the freely available MedOverNet (http://med. over.net/forum5/list.php?4) database, which includes several thousand cases. It consists of several forums, one of which is also a family medicine forum where questions can be asked by registered users. This forum is moderated by a specialist in family medicine.

Virtual cases are carefully selected by teachers in order to cover the learning aims of this assignment; primary care 
approach, holistic management, comprehensive management, and patient-involvement strategies. The virtual case has to include; a new presentation of a problem/symptom, a detailed description of the problem, and at least some information on the patient. Each student got a different virtual clinical case.

For this study, two teachers (JK and ZKK) independently assessed the short reports of the students using previously developed scoring sheets (assessment tool) already described elsewhere. ${ }^{17}$ Then, the mean value of scores of each item was calculated. ${ }^{17}$

The assessment tool consisted of ten items that could be answered on a 5-point Likert scale: 1 (unacceptable) to 5 (excellent). The maximum total score of the assessment scale was 50 points, and the minimal total score was 5 points. The tool covers four parts of the consultation: initial assessment, physical examination planning, planning patient management, and patient education/involvement. Initial assessment includes; determination of the reason for the encounter (management of the presenting problem). The physical examination planning includes; the planning of focused physical examination and seeking agreement with the patient (shared decision making). The planning patient management includes; the planning of which tests to perform, planning management of continuous problems, and seeking agreement with the patient (shared decision making). Lastly the patient education/involvement includes; shared decision making and health promotion/education. ${ }^{17}$

\section{Data analysis}

The data were analyzed using SPSS 13.0 (SPSS Inc., Chicago, IL, USA). Univariate statistics were performed. We performed bivariate analyses using the independent $t$-test. We set the level of statistical significance at $P<0.05$.

\section{Results}

Of 159 students, 12 did not complete the assignment. Therefore, the final sample consisted of 147 (92.5\%) student reports. There were $82(55.8 \%)$ reports from the study year 2009/2010 and 65 (44.2\%) from the study year 2010/2011. There were $95(64.6 \%)$ female students in the sample.

The mean total score on the assessment scale was 35.1 \pm 7.0 points (Table 1). Students scored higher in the initial assessment items and lower in the patient education/ involvement items (Tables 1 and 2). Female students scored significantly higher in terms of total assessment score and in terms of initial assessment and patient education/ involvement (Table 3).
Table I Assessment scores of individual items

\begin{tabular}{lc}
\hline Item & $\begin{array}{l}\text { Mean } \\
\text { score } \pm \text { SD }\end{array}$ \\
\hline $\begin{array}{l}\text { Student asked the appropriate questions regarding } \\
\text { patient's history }\end{array}$ & $4.1 \pm 0.8$ \\
Student proposed the appropriate differential diagnoses & $4.1 \pm 0.8$ \\
Student proposed the appropriate clinical examination & $3.4 \pm 1.3$ \\
Student proposed the appropriate investigations & $3.9 \pm 1.0$ \\
Student proposed the appropriate referrals & $3.7 \pm 1.2$ \\
Student proposed the appropriate management & $3.9 \pm 1.0$ \\
Student explained the planned investigations & $3.2 \pm 1.2$ \\
and referrals to patient & \\
Student explained the planned management to patient & $2.9 \pm 1.2$ \\
Student explained the probable diagnosis to patient & $2.7 \pm 1.2$ \\
Student gave the patient instructions & $3.1 \pm 1.1$ \\
on self-management at home & $35.1 \pm 7.0$ \\
\hline Total &
\end{tabular}

Abbreviation: SD, standard deviation.

\section{Discussion}

This study showed average overall knowledge in decision making among fourth-year medical students was highest in the initial assessment of the presenting problem and lowest in patient education and involvement in management. Female students showed significantly higher overall knowledge when compared to their male colleagues.

To the best of our knowledge, this is the first study to assess students' decision making, whilst including other aspects of consultation besides management of presenting problems. Not surprisingly, students showed good knowledge in initial assessment of presenting patients' symptoms. At Maribor Medical School, similarly to other medical schools, the first years of study are devoted to clinical subjects, ${ }^{5}$ with the exception of the early introduction of problembased learning. ${ }^{18}$ However, in spite of the fact that the problem-based learning approach combines the acquisition

Table 2 Percentage of students assessed between 4.0 and 5.0 points on individual items

\begin{tabular}{ll}
\hline Item & $\mathbf{n ~ ( \% )}$ \\
\hline $\begin{array}{l}\text { Student asked the appropriate questions regarding } \\
\text { patient's history }\end{array}$ & $103(70.1)$ \\
$\begin{array}{l}\text { Student proposed the appropriate differential diagnoses } \\
\text { Student proposed the appropriate clinical examination }\end{array}$ & 1 II (75.5) \\
Student proposed the appropriate investigations & $59(40.1)$ \\
Student proposed the appropriate referrals & $85(57.8)$ \\
Student proposed the appropriate management & $78(53.1)$ \\
Student explained the planned investigations & $83(56.5)$ \\
and referrals to patient & $60(40.8)$ \\
Student explained the planned management to patient & $42(28.6)$ \\
Student explained the probable diagnosis to patient & $25(17.0)$ \\
Student gave the patient instructions & $50(34.0)$ \\
on self-management at home & \\
\hline
\end{tabular}


Table 3 Individual items' assessment scores and the effect of sex

\begin{tabular}{|c|c|c|}
\hline Item & $\begin{array}{l}\text { Men versus women } \\
\text { (mean } \pm \text { SD) }\end{array}$ & $P$-value \\
\hline $\begin{array}{l}\text { Student asked the appropriate } \\
\text { questions regarding patient's } \\
\text { history }\end{array}$ & $3.8 \pm 0.8$ versus $4.2 \pm 0.7$ & $<0.001$ \\
\hline $\begin{array}{l}\text { Student proposed the } \\
\text { appropriate differential diagnoses }\end{array}$ & $3.9 \pm 0.8$ versus $4.3 \pm 0.7$ & 0.001 \\
\hline $\begin{array}{l}\text { Student proposed the } \\
\text { appropriate clinical examination }\end{array}$ & $3.2 \pm \mathrm{I} .1$ versus $3.5 \pm \mathrm{I} .3$ & 0.103 \\
\hline $\begin{array}{l}\text { Student proposed the } \\
\text { appropriate investigations }\end{array}$ & $3.7 \pm 1.0$ versus $4.0 \pm 1.0$ & 0.081 \\
\hline $\begin{array}{l}\text { Student proposed the } \\
\text { appropriate referrals }\end{array}$ & $3.5 \pm 1.1$ versus $3.8 \pm 1.2$ & 0.134 \\
\hline $\begin{array}{l}\text { Student proposed the } \\
\text { appropriate management }\end{array}$ & $3.7 \pm 1.0$ versus $4.0 \pm 1.0$ & 0.104 \\
\hline $\begin{array}{l}\text { Student explained the planned } \\
\text { investigations and referrals } \\
\text { to patient }\end{array}$ & $2.8 \pm 1.1$ versus $3.4 \pm 1.3$ & 0.009 \\
\hline $\begin{array}{l}\text { Student explained the planned } \\
\text { management to patient }\end{array}$ & $2.5 \pm \mathrm{I} . \mathrm{I}$ versus $3.2 \pm \mathrm{I} .2$ & $<0.001$ \\
\hline $\begin{array}{l}\text { Student explained the probable } \\
\text { diagnosis to patient }\end{array}$ & $2.4 \pm I . I$ versus $2.8 \pm I .2$ & 0.039 \\
\hline $\begin{array}{l}\text { Student gave the patient } \\
\text { instructions on self-management } \\
\text { at home }\end{array}$ & $2.9 \pm 1.2$ versus $3.3 \pm 1.1$ & 0.046 \\
\hline Total & $32.4 \pm 6.7$ versus $36.6 \pm 6.8$ & $<0.001$ \\
\hline
\end{tabular}

Abbreviation: SD, standard deviation.

of knowledge with the development of generic skills and attitudes, and aims to produce a better learning environment for gaining more practical knowledge in decision making, ${ }^{18}$ it does not incorporate knowledge, skills, and attitudes typical for family medicine. ${ }^{3}$ Therefore, students of Maribor Medical School are faced with a comprehensive and holistic family medicine approach to patients in only their fourth-year of study, which resulted in the findings of this study, where they scored lower in patient education and involvement.

Previous studies have shown that family physicians did not always include shared decision making when consulting patients. ${ }^{19-22}$ This was also shown by family medicine specialty exams, as one of the most common reasons for failing the consulting-skills assessment was an inability to fulfill or demonstrate the shared decision-making component. ${ }^{20}$ As this study demonstrated, undergraduate students also have problems with; explanation of planned management to patients, explanation of possible diagnosis to patients, and giving advice on patient management at home. With its unique concepts, family medicine should offer students as a whole the opportunity to learn these concepts and to apply them in practice as future medical doctors. ${ }^{23}$

As this study showed, female students outperformed males in terms of overall decision making, as well as in terms of initial assessment and patient education/involvement. Although some studies showed female students scored higher in exams and other academic activities compared to their male colleagues, ${ }^{12,13,24}$ no firm conclusions could be drawn from the literature at this point. Previous studies showed that there were sex (identity) learning style differences; male students used the meaning-directed learning style and the undirected learning style more often, and female students used the reproduction-directed learning style. ${ }^{10}$ Also, there were some sex differences in multimodal versus unimodal learning ${ }^{11}$ and deep versus surface approaches in learning, with deep learning being associated with female sex and higher academic success. ${ }^{13}$ However, none of these data could adequately explain the sex differences found in this study. As some evidence suggests, the differences could be due to findings that women have been reported to have greater abilities to listen actively and create better relationships with patients. ${ }^{25}$ In addition, it has already been speculated that women's higher clinical evaluation grades may reflect their better abilities in the areas of; cooperation, patient communication, interviewing, and counseling. ${ }^{26}$ On the other hand, the sex differences could be due to the superior writing abilities of the female students. However, it is obvious that further extensive research is needed in this area before any conclusions can be drawn.

The strengths of this study include; the use of a validated assessment score sheet, ${ }^{17}$ which enabled us to assess the other parts of the consultation and not only the clinical part. Therefore, the results of this study add considerably to the underresearched field of undergraduate student decision-making performance.

Limitations include the fact that the study was performed at the end of the semester in which family medicine is also taught. Therefore, students had already taken part in lectures, seminars, and exercises in family medicine. Since this study was a cross-sectional one and not an intervention one, we cannot judge the contribution of family medicine teaching on the students' testing performance. Therefore, it might be true that the students had already gained certain knowledge on a typical family medicine approach to patients, and the assessment scores might have been lower if they had been assessed at the beginning of the semester before teaching in family medicine had started. Another limitation lies in the fact that the students got different virtual clinical cases, which might have differentiated according to their difficulty. This could also be a source of a bias in terms of presented sex differences. Another limitation is the fact that the teachers who performed the grading (one of them was male and the other female) could have performed a biased grading. 


\section{Conclusion}

Knowledge in decision making in undergraduate students is mostly concentrated on clinical management of presenting problems. Students seem to be less focused on patient management specific to family medicine, ie, a holistic and comprehensive approach, and primary care management with preventive and counseling activities. Undergraduate medical education should devote more time to teaching the comprehensive approach to consultation, especially the modification of health behavior of patients and opportunistic health promotion to patients. The sex differences found in this study are difficult to explain, and require further focused research. Also, the effect of the family medicine approach to teaching on decision making should be evaluated in prospective intervention studies.

\section{Author contributions}

ZKK and JK conceived and coordinated the study. ZKK carried out the data analysis and ZKK and JK interpreted the results. Both authors drafted, revised and approved the final manuscript.

\section{Disclosure}

The authors report no conflicts of interest in this work.

\section{References}

1. Krzton-Królewiecka A, Svab I, Oleszczyk M, Seifert B, Smithson WH, Windak A. The development of academic family medicine in central and eastern Europe since 1990. BMC Fam Pract. 2013;14:37.

2. Svab I. Education in medicine. Zdrav Var. 2012;51:225-226.

3. Heyrman J. EURACT Educational Agenda. Leuven: European Academy of Teachers in General Practice; 2005.

4. Stott NC, Davis RH. The exceptional potential in each primary care consultation. J R Coll Gen Pract. 1979;29(201):201-205.

5. Rabadán FE, Hidalgo JL. Changes in the knowledge of and attitudes toward family medicine after completing a primary care course. Fam Med. 2010;42(1):35-40.

6. McGregor CA, Paton C, Thomson C, Chandratilake M, Scott H. Preparing medical students for clinical decision making: a pilot study exploring how students make decisions and the perceived impact of a clinical decision making teaching intervention. Med Teach. 2012;34(7):e508-e517.

7. Williams RG, Klamen DL. Examining the diagnostic justification abilities of fourth-year medical students. Acad Med. 2012;87(8):1008-1014.

8. Coderre S, Jenkins D, McLaughlin K. Qualitative differences in knowledge structure are associated with diagnostic performance in medical students. Adv Health Sci Educ Theory Pract. 2009;14(5):677-684.
9. Makinen J, Manninen SM, Lehto S, Perheentupa A. Challenges in training and its assessment: a survey of ob-gyn trainees in the University of Turku, Finland. Zdrav Var. 2012;51:261-269.

10. Severiens S, Dam GT. Gender and gender identity differences in learning styles. Educ Psychol. 1997;17(1):79-93.

11. Slater JA, Lujan HL, DiCarlo SE. Does gender influence learning style preferences of first-year medical students? Adv Physiol Educ. 2007;31(4):336-342.

12. Kassab S, Abu-Hijleh M, Al-Shboul Q, Hamdy H. Gender-related differences in learning in student-led PBL tutorials. Educ Health (Abingdon). 2005;18(2):272-282.

13. Mattick K, Dennis I, Bligh J. Approaches to learning and studying in medical students: validation of a revised inventory and its relation to student characteristics and performance. Med Educ. 2004;38(5) 535-543.

14. Ramsbottom-Lucier M, Johnson MM, Elam CL. Age and gender differences in students' preadmission qualifications and medical school performances. Acad Med. 1995;70(3):236-239.

15. Kies SM, Williams BD, Freund GG. Gender plays no role in student ability to perform on computer-based examinations. BMC Med Educ. 2006;6(1):57-57.

16. Klemenc-Ketis Z, Kersnik J. The role of the European Academy of Teachers in General Practice and Family Medicine in family medicine education in Europe - the experience of the University of Maribor. Acta Med Acad. 2012;41(1):80-87.

17. Klemenc-Ketis Z, Kersnik J. New virtual case-based assessment method for decision making in undergraduate students: a scale development and validation. BMC Med Educ. 2013;13:160

18. Wood DF. Problem based learning. BMJ. 2008;336(7651):971.

19. Saba GW, Wong ST, Schillinger D, et al. Shared decision making and the experience of partnership in primary care. Ann Fam Med. 2006;4(1): 54-62

20. Siriwardena AN, Edwards AG, Campion P, Freeman A, Elwyn G. Involve the patient and pass the MRCGP: investigating shared decision making in a consulting skills examination using a validated instrument. $\mathrm{Br} J$ Gen Pract. 2006;56(532):857-862.

21. Elwyn G, Edwards A, Kinnersley P. Shared decision-making in primary care: the neglected second half of the consultation. Br J Gen Pract. 1999;49(443):477-482.

22. Edwards A, Elwyn G, Wood F, Atwell C, Prior L, Houston H. Shared decision making and risk communication in practice: a qualitative study of GPs' experiences. Br J Gen Pract. 2005;55(510):6-13.

23. Svab I. Possibilities of family medicine in medical education. Acta Med Acad. 2012;41(1):59-63.

24. Simon SR, Bui A, Day S, Berti D, Volkan K. The relationship between second-year medical students' OSCE scores and USMLE Step 2 scores. J Eval Clin Pract. 2007;13(6):901-905.

25. Haist SA, Witzke DB, Quinlivan S, Murphy-Spencer A, Wilson JF. Clinical skills as demonstrated by a comprehensive clinical performance examination: who performs better - men or women? Adv Health Sci Educ Theory Pract. 2003;8(3):189-199.

26. Dixon D. Gender differences in academic qualifications and medical school performance of osteopathic medical students. Med Sci Educ. 2007;17(1):33-37.

\section{Publish your work in this journal}

Advances in Medical Education and Practice is an international, peerreviewed, open access journal that aims to present and publish research on Medical Education covering medical, dental, nursing and allied health care professional education. The journal covers undergraduate education, postgraduate training and continuing medical education

\section{Dovepress}

including emerging trends and innovative models linking education, research, and health care services. The manuscript management system is completely online and includes a very quick and fair peer-review system. Visit http://www.dovepress.com/testimonials.php to read real quotes from published authors. 